\title{
Germacrone alleviates neurological deficits following traumatic brain injury by modulating neuroinflammation and oxidative stress
}

Sujing Zhuang ${ }^{1}$, Baogui Liu², Shifeng Guo ${ }^{1}$, Yanzhong Xue ${ }^{1}$, Lin Wư ${ }^{3}$ Shiqi Liư ${ }^{4}$ Chunling Zhang ${ }^{3}$ and Xiuyan $\mathrm{Ni}^{5^{*}}$ iD

\begin{abstract}
Background: Germacrone (GM) is a terpenoid compound which is reported to have anti-inflammatory and antioxidative effects. However, its role in treating traumatic brain injury (TBI) remains largely unknown.

Methods: Male C57BL/6 mice were divided into the following groups: control group, TBI group [controlled cortical impact (CCl) model], CCl $+5 \mathrm{mg} / \mathrm{kg}$ GM group, $\mathrm{CCl}+10 \mathrm{mg} / \mathrm{kg}$ GM group and $\mathrm{CCl}+20 \mathrm{mg} / \mathrm{kg} \mathrm{GM}$ group. GM was administered via intraperitoneal injection. The neurological functions (including motor coordination, spatial learning and memory abilities) and brain edema were measured. Nissl staining was used to detect the neuronal apoptosis. Colorimetric assays and enzyme linked immunosorbent assay (ELISA) kits were used to determine the expression levels of oxidative stress markers including myeloperoxidase (MPO), malondialdehyde (MDA) and superoxide dismutase (SOD), as well as the expressions of inflammatory markers, including tumor necrosis factor a (TNF-a), interleukin-1 $\beta$ (IL-1 $\beta$ ) and interleukin-6 (IL-6). Additionally, protein levels of Nrf2 and p-p65 were detected by Western blot assay.

Results: GM significantly ameliorated motor dysfunction, spatial learning and memory deficits of the mice induced by TBI and it also reduced neuronal apoptosis and microglial activation in a dose-dependent manner. Besides, GM treatment reduced neuroinflammation and oxidative stress compared to those in the CCl group in a dosedependent manner. Furthermore, GM up-regulated the expression of antioxidant protein Nrf2 and inhibited the expression of inflammatory response protein p-p65.
\end{abstract}

Conclusions: GM is a promising drug to improve the functional recovery after TBI via repressing neuroinflammation and oxidative stress.

Keywords: Germacrone, Traumatic brain injury, NF-KB, Inflammation

\footnotetext{
*Correspondence: mgpifnuxiemu8211@163.com

${ }^{5}$ Department of Radiotherapy, Linyi Central Hospital, Linyi 276400, Shandong,

China

Full list of author information is available at the end of the article
}

(c) The Author(s). 2021 Open Access This article is licensed under a Creative Commons Attribution 4.0 International License, which permits use, sharing, adaptation, distribution and reproduction in any medium or format, as long as you give appropriate credit to the original author(s) and the source, provide a link to the Creative Commons licence, and indicate if changes were made. The images or other third party material in this article are included in the article's Creative Commons licence, unless indicated otherwise in a credit line to the material. If material is not included in the article's Creative Commons licence and your intended use is not permitted by statutory regulation or exceeds the permitted use, you will need to obtain permission directly from the copyright holder. To view a copy of this licence, visit http://creativecommons.org/licenses/by/4.0/ The Creative Commons Public Domain Dedication waiver (http://creativecommons.org/publicdomain/zero/1.0/) applies to the data made available in this article, unless otherwise stated in a credit line to the data. 


\section{Background}

Traumatic brain injury (TBI) is one of the common causes of disability and death. Patients with TBI often have cognitive dysregulation, dyskinesia, memory impairment and other neurological problems [1]. TBI has both a direct mechanical effect (primary injury) and an indirect effect caused by a complex pathological cascade (secondary injury). Subsequent biological processes trigger the secondary damage, such as excitotoxicity, which gives rise to many biological events, including the delayed afterdepolarization, inflammation and neuronal apoptosis around the lesion [2]. Preventing or ameliorating secondary brain injury has great significance to improve the prognosis of the patients with TBI.

Neuronal inflammation caused by activation of microglia figures prominently in secondary injury in TBI [3, 4], which can result in post-traumatic epilepsy and increase the risk of cognitive impairment and other sequelae [5]. After TBI, microglia are activated, and peripheral macrophages migrate to the injured site and secrete a large number of inflammatory cytokines, such as tumor necrosis factors, interleukins and interferons, which contribute to inflammatory response and neuronal apoptosis [6]. NF-kB signaling plays a key role in regulating the expression and activation of NLRP1 and NLRP3 inflammasomes in neurons and brain tissue [7]. Besides, inhibition of NF-KB signaling pathway can prevent acute brain injury by inhibiting excessive microglial activation and promoting neuronal survival [8]. In addition, excessive activation of microglia produces reactive oxygen species (ROS). Excessive ROS interferes with the normal structure and the function of proteins and lipids, inducing DNA damage and cellular apoptosis [9]. Nuclear factor, erythroid 2 like 2 (Nrf2) is a basic leucine zipper (bZIP) transcription factor and a crucial regulator for inducing the expressions of antioxidant proteins and preventing oxidative damage [10-12]. For example, Nrf2 participates in the brain's defense mechanism to protect itself from ischemia-reperfusion injury [11].

Germacrone (GM) is one of the main bioactive components extracted from Curcuma zedoaria Roscoe, which has a wide range of biological effects such as antiinflammation, anti-oxidation and anti-tumor functions [13-15]. It is reported that GM blocks the progression of arthritis by regulating Th1/Th2 balance and inhibiting NF- $\mathrm{kB}$ signaling [16]. What's more, GM can markedly reduce the expressions of the pro-inflammatory cytokines IL- 6 and TNF- $\alpha$, while promoting the expressions of the anti-inflammatory mediators TGF- $\beta$ and IL-10, and has a protective effect on the acute lung injury caused by lipopolysaccharide in newborn rats [17]. Additionally, GM reduces neurological injury caused by cerebral ischemia-reperfusion in rats through antioxidant and anti-apoptotic mechanisms [15]. However, its neuroprotective functions in TBI have not been explored.

The purpose of this study was to study the neuroprotective effects of GM on a mice model with TBI, and to investigate the underlying molecular mechanisms.

\section{Methods}

\section{Animal model}

Male C57BL/6 mice aged from 7 to 8 weeks (weight about $20-23 \mathrm{~g}$ ) were purchased from the Model Animal Research Center of Nanjing University (Nanjing, China). The mice were raised in a controlled environment (12-h light / 12-h dark cycle, $22 \pm 2{ }^{\circ} \mathrm{C}, 40-60 \%$ humidity) and supplied with enough food and water. All of the procedures in animal experiments in this work were approved by the Institutional Animal Care and Use Committee of Affiliated Hospital of Jining Medical University.

Fifty mice were randomly divided into 5 groups (10 mice per group): 1. Control (sham) group; 2. TBI (controlled cortical impact [CCI]) group; 3 . CCI $+5 \mathrm{mg} / \mathrm{kg}$ GM group (CCI mice treated with $5 \mathrm{mg} / \mathrm{kg}$ GM), 4 . $\mathrm{CCI}+10 \mathrm{mg} / \mathrm{kg}$ GM group (CCI mice treated with 10 $\mathrm{mg} / \mathrm{kg} \mathrm{GM}$ ) and $5 . \mathrm{CCI}+20 \mathrm{mg} / \mathrm{kg}$ GM group (CCI mice treated with $20 \mathrm{mg} / \mathrm{kg} \mathrm{GM}$ ). $2 \mathrm{~h}$ after CCI, in GM treatment groups, the mice were intraperitoneally injected with 5, 10 and $20 \mathrm{mg} / \mathrm{kg}$ GM (Fig.1, SigmaAldrich, St. Louis., MO, USA). Mice in the CCI and control groups were administrated with normal saline. The dosing, delivery route and treatment regimens were based on previous studies $[16,18]$. There was no significant difference in body weight and blood glucose in GM-treated mice compared with those in the mice in CCI group and control group (data not shown). After GM treatment, some of the mice (4 mice per group) were sacrificed with asphyxia $\left(20 \% \mathrm{CO}_{2}\right.$ for $\left.10 \mathrm{~min}\right)$, and the brain tissues were collected for subsequent examinations, and the neurological functions were evaluated with the other mice (6 mice per group).

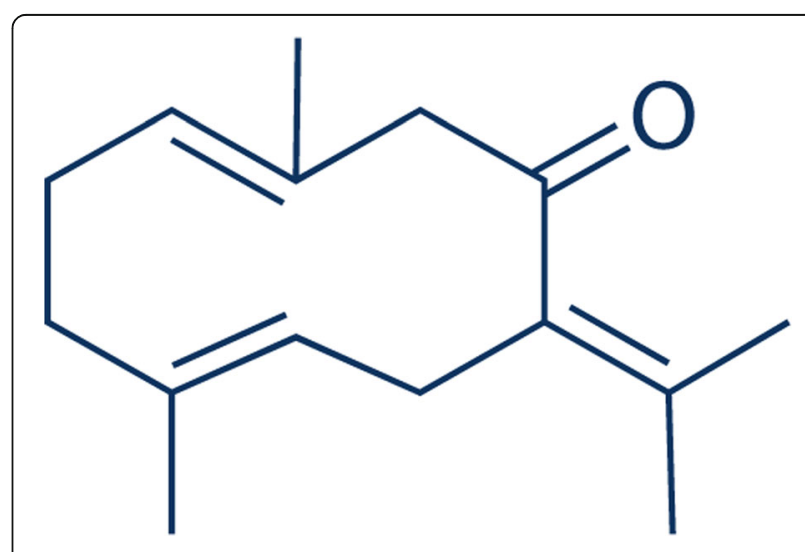

Fig. 1 The molecular structure of GM 
TBI animal model was established by CCI. In brief, the surgery was performed after the mice were anaesthetized with isoflurane (2\%). After craniotomy, CCI was conducted with a stainless-steel pointed piston with a diameter of $3 \mathrm{~mm}$ in a stereotactic impactor (Leica, Wetzlar, Germany), centered at $2 \mathrm{~mm}$ posterior to bregma and $2.5 \mathrm{~mm}$ left of midline [19]. The piston speed was set at $5 \mathrm{~m} / \mathrm{s}$ and the depth of $1.5 \mathrm{~mm}$, and a moderate cortical contusion was produced in the left lobe of the brain [20]. In the sham group, the mice were anesthetized with isoflurane and then craniotomy was performed, without traumatic induction.

\section{Rota-rod test and Morris water maze assay}

The rota-rod assay was used to assess motor function and the balance of the mice. The day before the experiment began, the mice were placed on a rotating rod at a constant speed of $4 \mathrm{rpm}$ in order to get accustomed to the LE8200 rota-rod device (Letica Scientific Instruments, Spain). After the experiment began, each mouse was placed on the accelerating rotating rod (at a speed of 4 to $40 \mathrm{rpm}$ in $5 \mathrm{~min}$ ). The experiment was repeated for three times for each animal, and the average time during which an animal could maintain itself on the device was recorded.

Morris water maze assay was used to evaluate the spatial learning and memory of the mice as previously described [21]. Briefly, the mice were placed in a black round tank (with a diameter of $150 \mathrm{~cm}$ ) filled with water. The mice were trained to swim to a hidden platform four times a day for seven consecutive days before the experiment. If the mice found the platform in $60 \mathrm{~s}$ and stayed on it for $10 \mathrm{~s}$, they would be taken out of the swimming pool. If the mice could not find the platform within $60 \mathrm{~s}$, they were gently guided to the platform and allowed to stay on the platform for another $20 \mathrm{~s}$. After the experiment began, the platform was removed. The mice were allowed to swim freely for $60 \mathrm{~s}$. The number of times that the mice passed through the platform area and the time spent in the quadrant with the platform area were recorded as the scores.

\section{Hematoxylin and eosin (HE) staining and Nissl's staining}

After the mice were deeply anesthetized, the chest was opened and the hearts were perfused with normal saline until colorless liquid flowed from right auricle. Then the mice were perfused with $4 \%$ paraformaldehyde, and the brains of the mice were obtained and fixed in $10 \%$ formaldehyde for $24 \mathrm{~h}$. After the specimens were embedded in paraffin and sliced (into $4 \mathrm{~mm}$ thick sections), the sections containing the hippocampal tissues were used for HE staining, and the sections were observed under a light microscope (Nikon, Tokyo, Japan).
After dewaxing and rehydration, the sections were stained with Nissl staining solution (Beyotime, Shanghai, China) for $30 \mathrm{~min}$ at $60^{\circ} \mathrm{C}$, dehydrated with ethanol, made transparent with xylene and sealed with neutral gum, and the sections were observed and photographed under a microscope (Nikon, Tokyo, Japan).

\section{Evaluation of brain edema}

After TBI, the hemisphere with the lesion of the mice was removed and weighed to obtain a wet weight. Then the brain tissues were placed in an oven and dried for $24 \mathrm{~h}$, and then the dried brain tissues were weighed to obtain a dry weight. Brain water content (\%) was calculated according to the formula: (wet weight-dry weight)/ wet weight $\times 100 \%$.

\section{Evaluation of inflammatory responses and oxidative stress}

The brain tissue of the mice was homogenized on ice and the supernatant was collected by centrifugation at $2500 \times \mathrm{g}$ for $20 \mathrm{~min}$. Then the concentrations of inflammatory cytokines TNF- $\alpha$, IL- $1 \beta$ and IL- 6 in brain tissues were measured with enzyme-linked immunosorbent assay (ELISA) method according to the manufacturer's instructions using corresponding ELISA kit (Solarbio, Beijing, China). Colorimetric methods were used to determine the activities of myeloperoxidase (MPO), malondialdehyde (MDA) and superoxide dismutase (SOD). The kits for detecting the above oxidative stress indicators were purchased from Solarbio (Beijing, China).

\section{Quantitative real-time polymerase chain reaction (qRT- PCR)}

Total RNA was isolated using TRIzol reagent (Invitrogen, Carlsbad, CA) in line with the manufacturer's instructions. The RNA was reversely transcribed into cDNA using PrimeScript ${ }^{\mathrm{TM}} \mathrm{RT}$ reagent Kit with gDNA Eraser (Takara, Dalian, China). The SYBR ${ }^{\circledR}$ Premix Ex Taq $^{\text {TM }}$ II (Takara, Dalian, China) was used to perform qRT-PCR assay. Relative quantification of the genes was performed using $2^{-\Delta \Delta C t}$ method and glyceraldehyde 3phosphate dehydrogenase (GAPDH) was used as the reference gene. Specific primers were as follows: CD11b primers: forward: 5'-ATGGACGCTGATGGCAAT ACC-3 'and reverse: 5'-TCCCCATTCACGTCTCCCA3'; CD16 primers: forward: 5'-CAGAATGCACACTC TGGAAGC-3 'and reverse: 5'-GGGTCCCTTCGCAC ATAG-3 ‘; TNF- $\alpha$ primers: forward: 5’-CCCTCACACT CAGATCATCTTCT-3' and reverse: 5'-GCTACGAC GTGGGCTACAG-3 '; IL-6 primers: forward: 5'-TAGT CCTTCCTCTACCCCAATTTCC-3' and reverse: 5' TGGTCCTTAGCCACTCCTTCTC -3 ‘; IL-1 $\beta$ primers: forward: 5'-GCAACTGTTCCTGAACTCAACT-3’ and reverse: 5'-ATCTTTTGGGGTCCGTCAACT-3 '; 
GAPDH primers: forward: 5'-TCATCCCAGAGCTGAA CG-3' and reverse: 5' ${ }^{\prime}$-TCATACTTGGCAGGTTTC TCC $-3^{\prime}$.

\section{Western blot assay}

Proteins from brain tissues (homogenized) were extracted using RIPA buffer (Biosharp, Hefei, China) and quantified using a bicinchoninic acid kit (Biosharp, Hefei, China). The extractive was heated in boiling water for $10 \mathrm{~min}$, then separated by $10 \%$ sodium dodecyl sulfate-polyacrylamide gel electrophoresis and transferred to a PVDF membrane (Millipore, Bedford, MA, USA). The membrane was blocked with $5 \%$ skim milk and then incubated with primary antibodies anti-Nrf2 (1: 1000; ab62352; Abcam), anti-NF-kB phosphorylated p65 (p-p65) (S536) (1: 1000; ab86299; Abcam), antiCD16 (1: 1000; ab203883; Abcam), anti-CD11b (1: 1000; ab13357; Abcam) and anti- $\beta$-actin (1: 1000; ab8226; Abcam), respectively, followed by being gently shaken at $4{ }^{\circ} \mathrm{C}$ overnight. The membranes were then rinsed with TBST and incubated with the corresponding horseradish peroxidase (HRP)-conjugated secondary antibodies (Proteintech, Wuhan, China) for $1 \mathrm{~h}$ at room temperature. Finally, electrochemiluminescence kit (Biosharp, Hefei, China) was used for developing the protein bands. The gray value of each band was analyzed with the software ImageJ (NIH, Bethesda, MD, USA).

\section{Statistical analysis}

The results in this study were expressed as mean \pm standard deviation $(\mathrm{x} \pm \mathrm{s})$ and SPSS statistical software (version 22.0, Chicago, IL, USA) was used to analyze the data. The data in two groups were compared using $t$-test and the data in multiple groups were compared using one-way ANOVA. GraphPad Prism 6.0 (GraphPad Software, San Diego, CA, USA) was used for graphing. $P<$ 0.05 was considered statistically significant.

\section{Results \\ GM ameliorated neurological dysfunction and neurological injury in $\mathrm{CCl}$ mice}

To evaluate the neuroprotective effect of GM on TBI in mice, the mice model with TBI was treated with 5,10 or $20 \mathrm{mg} / \mathrm{kg}$ GM. The motor function, spatial learning and memory abilities of mice were detected by rota-rod test and Morris water maze assay. The results depicted that compared with in sham group, the above functions were decreased dramatically in mice with TBI while GM remarkably improved the motor function, spatial learning and memory functions in a dose-dependent manner (vs. CCI group, Fig. 2a-c). HE staining of hippocampal tissues unearthed that GM reduced the edema in the extracellular space and surrounding blood vessels, and wetdry method also indicated that cerebral edema of the mice was also markedly ameliorated by GM treatment (vs. CCI group, Fig. 2d). Besides, the results of Nissl staining manifested that, in the control group, neurons are with clear cell outline, and the cellular structure was intact with abundant cytoplasm; in CCI group, damaged neuron was present with deformation and condensation of cytoplasm and nuclei; however, GM treatment partly reversed the pathological changes (vs. CCI group, Fig. 2e). These findings demonstrated that GM could ameliorate the neurological injury caused by CCI.

\section{GM reduced microglial activation in $\mathrm{CCI}$ mice}

Reportedly, microglial activation is closely related to the secondary injury after TBI $[3,4]$. In this study, the mRNA and protein levels of microglial activation markers CD16 and CD11b in the brain tissues of the mice in each group were detected by qRT-PCR and Western blot assays. The results showed that microglia were activated in the brain tissue of mice with TBI: the mRNA and protein expression levels of the two markers of activated microglia, CD16 and CD11b, were significantly increased in $\mathrm{CCI}$ group, while GM treatment observably decreased the expressions of CD16 and CD11b (Fig. 3a-c). These results suggested that GM inhibited microglial activation after TBI.

\section{GM reduces the levels of pro-inflammatory cytokines in the brain tissues of the mice with TBI}

Neuroinflammation after TBI is closely associated with microglial activation [6]. To observe the difference of pro-inflammatory cytokines' expressions of the mice in different groups, qRT-PCR and ELISA assays were performed. qRT-PCR assay verified that after CCI, expressions of TNF- $\alpha$, IL- 6 and IL- $1 \beta$ mRNA were markedly increased (vs. sham group), and the GM treatment $(5,10$ and $20 \mathrm{mg} / \mathrm{kg}$ ) notably repressed the expressions of TNF- $\alpha$, IL- $1 \beta$ and IL- 6 in a dose-dependent manner (vs. CCI group, Fig. 4a-c). Consistently, ELISA unmasked that after TBI, TNF- $\alpha$, IL- 6 and IL- $1 \beta$ expressions in the brain tissues of the mice were dramatically increased (vs. sham group) and gradually decreased with the treatment of higher doses of GM (vs. CCI group, Fig. 4d-f). Therefore, it was concluded that GM could suppress the inflammatory response in brain after TBI.

\section{GM reduced oxidative stress in $\mathrm{CCI}$ mice}

To further expound the effect of GM on oxidative stress, the oxidative stress in the brain of mice in different groups was analyzed. Compared with the sham group, MPO activity and MDA level in the brain tissue of mice treated with CCI were significantly enhanced; MPO and MDA were markedly inhibited after GM treatments (vs. CCI group, Fig. 5a-b). Moreover, compared with in the sham group, SOD activity in the brain tissues of the 


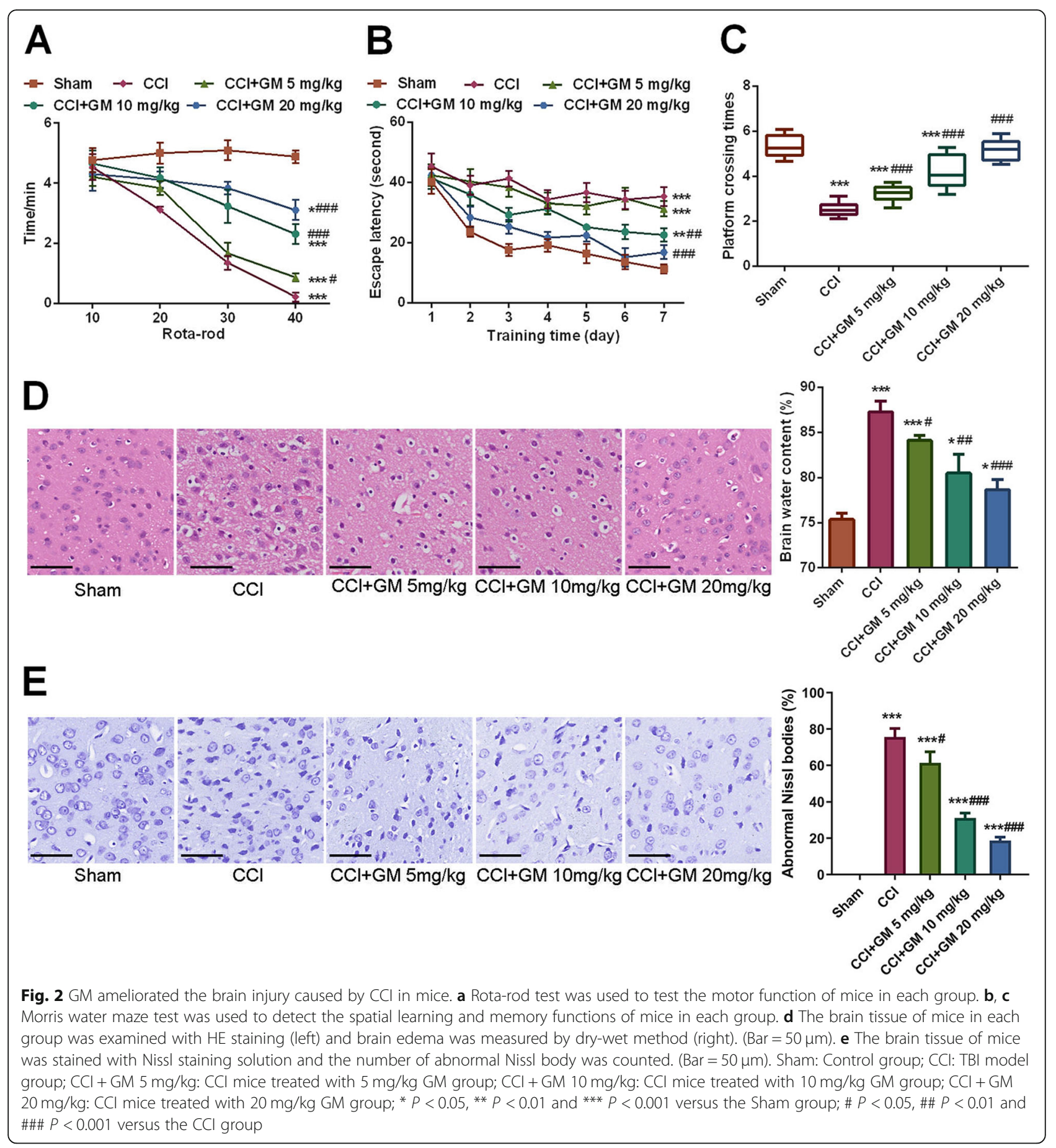

mice in the CCI group was significantly reduced; conversely, GM could markedly increase the expression level of SOD in CCI mice (vs. CCI group, Fig. 5c).

\section{GM induced anti-oxidative and anti-inflammatory responses via regulating Nrf2 and NF-KB pathways} The above results showed that GM could remarkably inhibit the inflammation and oxidative stress induced by CCI. NF- $\mathrm{kB}$ exerts a crucial role in regulating downstream inflammatory cytokines and mediators; Nrf2 is an essential endogenous transcription factor in cells to defend against oxidative stress [7-12]. Western blot assay indicated that compared with in the sham group, the expression of p-p65 in mice of CCI group was increased, suggesting that NF- $\mathrm{kB}$ signaling was activated, while GM treatment could significantly inhibit the excessive expression of p-p65 (vs. CCI group, Fig. 6). Western blot assay also suggested that GM could induce 


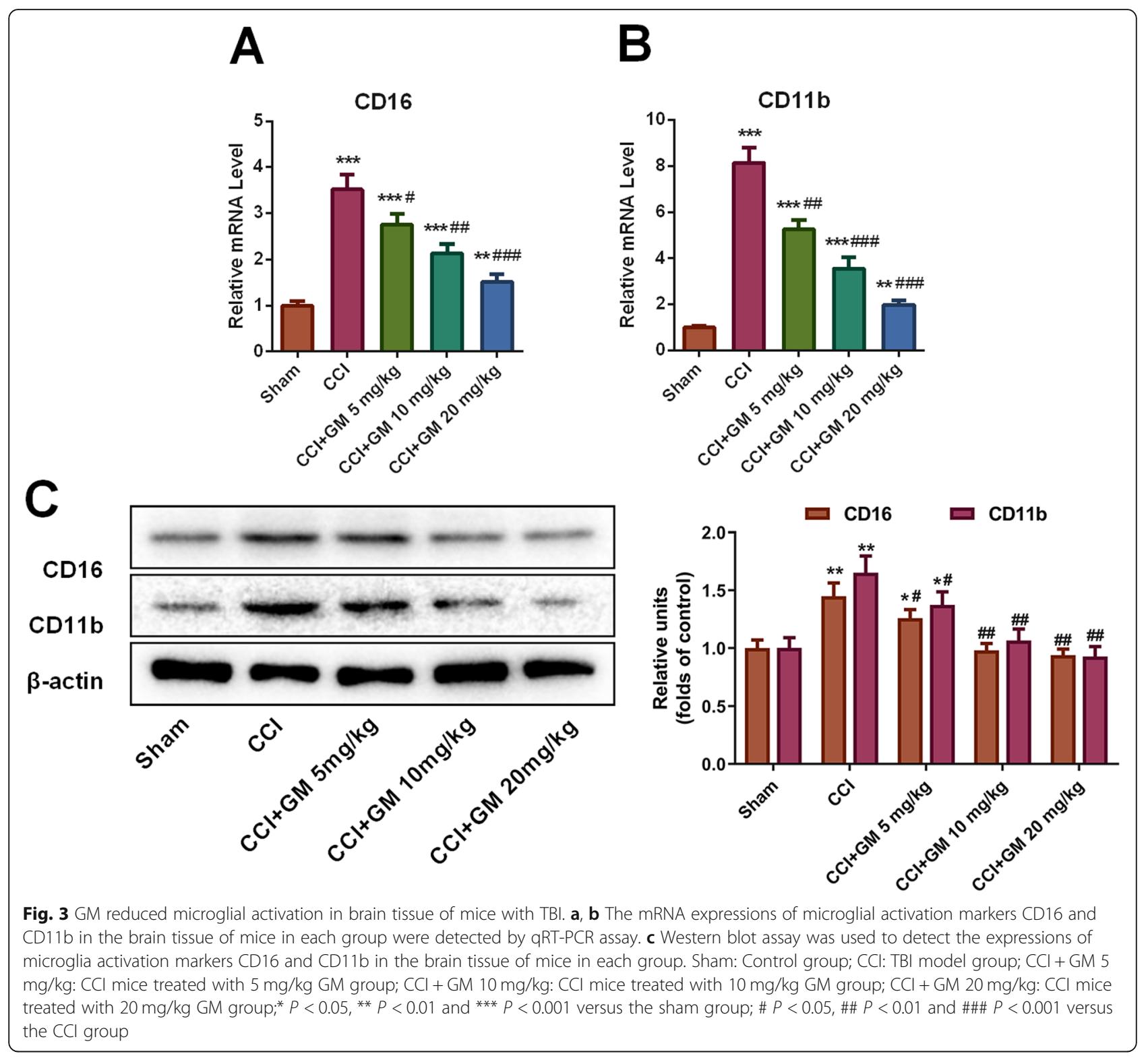

the expression of Nrf2 to exert antioxidant effects (vs. CCI group, Fig. 6). Therefore, we supposed that GM could probably exert anti-inflammatory and antioxidative effects via regulating the NF- $\mathrm{kB}$ and Nrf2 pathways.

\section{Discussion}

Inflammatory response and oxidative stress are considered to be the main biological events participating in the secondary brain injury caused by TBI [22]. In this study, we found that GM treatment could ameliorate the secondary brain injury with a mice model with TBI, accompanied by better motor function and spatial memory, reduced brain edema, less severe neuroinflammation and oxidative stress. Besides, it was demonstrated that GM could probably suppress NF- $\mathrm{KB}$ signaling and activate Nrf2 pathway. Our data suggested that GM was a promising drug to prevent or ameliorate the secondary brain injury induced by TBI.

In a rat model with cerebral ischemia, GM treatment attenuates ischemia/reperfusion-induced the brain injury of animals: GM treatment reduces MDA expression level and promotes the activities of glutathione, SOD and glutathione peroxidase; GM treatment also decreases the expressions of caspase- 3 and Bax, and increases the expression of Bcl-2 [15]. Another study proves that GM treatment can ameliorate the brain injury of rats caused by middle cerebral artery occlusion/reperfusion, via regulating PI3K/Akt/mTOR signaling and repressing autophagy [23]. It is well known that hippocampal neuron 


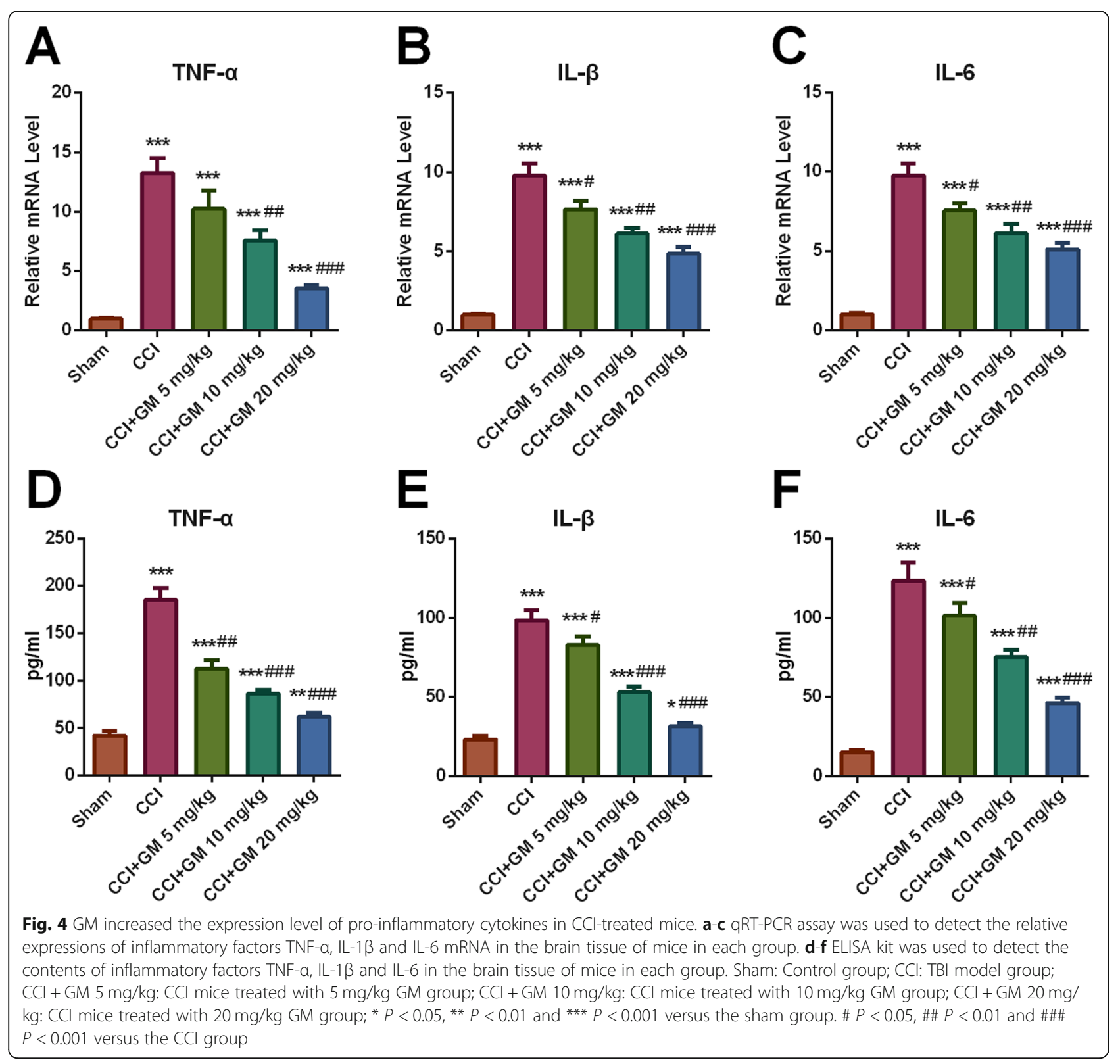

death is closely linked to the dysfunction of learning and memory [24]. In the present work, we demonstrated that GM could attenuate the edema and neuron injury of hippocampal tissues induced by TBI, accompanied by improved spatial learning and memory abilities. Additionally, after the mice with TBI were treated with GM, the motor function was also improved. Our data further validated that GM had neuroprotective properties, which is consistent with the previous reports [15, 23].

Microglia are the smallest glial cells, which are distributed throughout the central nervous system, accounting for about $5-10 \%$ of total glial cells [25]. The activation of microglia and the release of inflammatory cytokines are key factors in the inflammatory response in nervous system after injury [26]. In this study, we found that GM could remarkably suppress the expressions of microglial activation markers CD16 and CD11b, suggesting GM could repress the activation of microglial cells. Our results also authenticated that GM could significantly inhibit the expressions of inflammatory cytokines, including TNF- $\alpha$, IL- 6 and IL- $1 \beta$, thus suppressing the inflammatory response. NF- $\mathrm{kB}$ is one of the key regulators of inflammation after brain injury $[27,28]$. Therefore, in this study, the expression of NF-kB was further analyzed by Western blot assay. The results manifested that NF- $\mathrm{KB}$ was over-activated in the brain tissues of the mice in CCI group, but the phosphorylation of p65 was markedly blocked by GM treatment. These results 

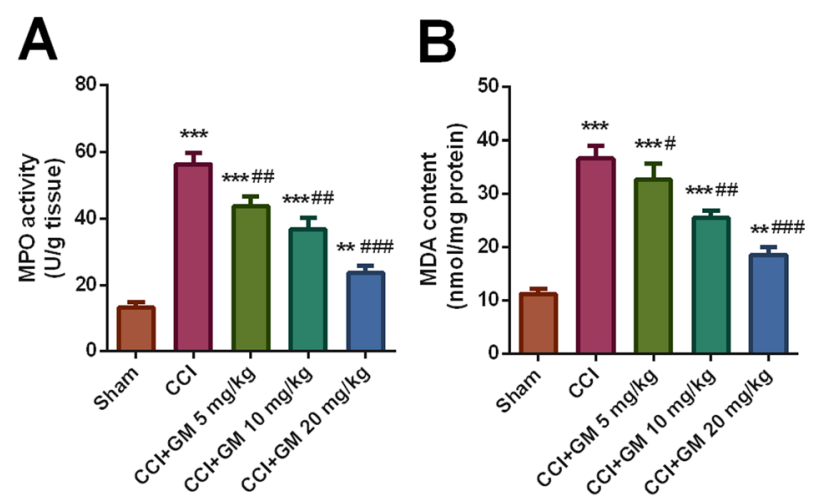

C

Fig. 5 GM reduced oxidative stress response in CCl-treated mice. a-c. The activity of MPO, the content of MDA and the activity of SOD in the brain tissue of mice in each treatment group were detected with corresponding kits. Sham: Control group; CCl: TBI model group; CCI + GM 5 mg/ kg: CCl mice treated with $5 \mathrm{mg} / \mathrm{kg}$ GM group; $\mathrm{CCl}+\mathrm{GM} 10 \mathrm{mg} / \mathrm{kg}$ : CCl mice treated with $10 \mathrm{mg} / \mathrm{kg} \mathrm{GM}$ group; $\mathrm{CCl}+\mathrm{GM} 20 \mathrm{mg} / \mathrm{kg}: \mathrm{CCl}$ mice treated with $20 \mathrm{mg} / \mathrm{kg} \mathrm{GM}$ group; ${ }^{*} P<0.05$, ${ }^{* *} P<0.01$ and ${ }^{* *} P<0.001$ versus the sham group; $\# P<0.05$, \#\# $P<0.01$ and \#\#\# $P<0.001$ versus the CCl group

indicated that GM might have a neuroprotective effect via inhibiting the activation of NF-kB signaling.

Oxidative stress features prominently in the occurrence of secondary injuries [29]. In neurons, the increase of ROS triggers DNA damage and neuronal apoptosis. Nrf2 modulates hundreds of genes, of which many are involved in regulating ferroptosis, metabolism of glutathione, iron and lipids homeostasis and mitochondrial function, and the activation of Nrf2/ARE signaling, which up-regulates the expressions of antioxidant genes, such as HO-1 and NQO1, shows neuroprotective functions in animal models of cerebral ischemia, Parkinson's disease, Alzheimer's disease and amyotrophic lateral sclerosis $[30,31]$. Activating $\mathrm{Nrf2}$ signaling is a promising strategy to attenuate the secondary injury after TBI. For example, valproate treatment promotes the activity of Nrf2/ARE pathway and inhibits the autophagy of neurons after TBI, alleviating neurological impairment, including brain edema and neuronal apoptosis in a rat model [32]. In this study, we found that content of MDA and MPO activity in the brain tissue of GM-treated mice was dramatically reduced and the SOD activity was dramatically increased, suggesting that GM inhibited the oxidative stress response induced by TBI. Further analysis of the Nrf2 protein revealed that GM treatment remarkably facilitated the expression of Nrf2, indicating that GM-mediated anti-oxidative effects might be caused by the activation of Nrf2 pathway.

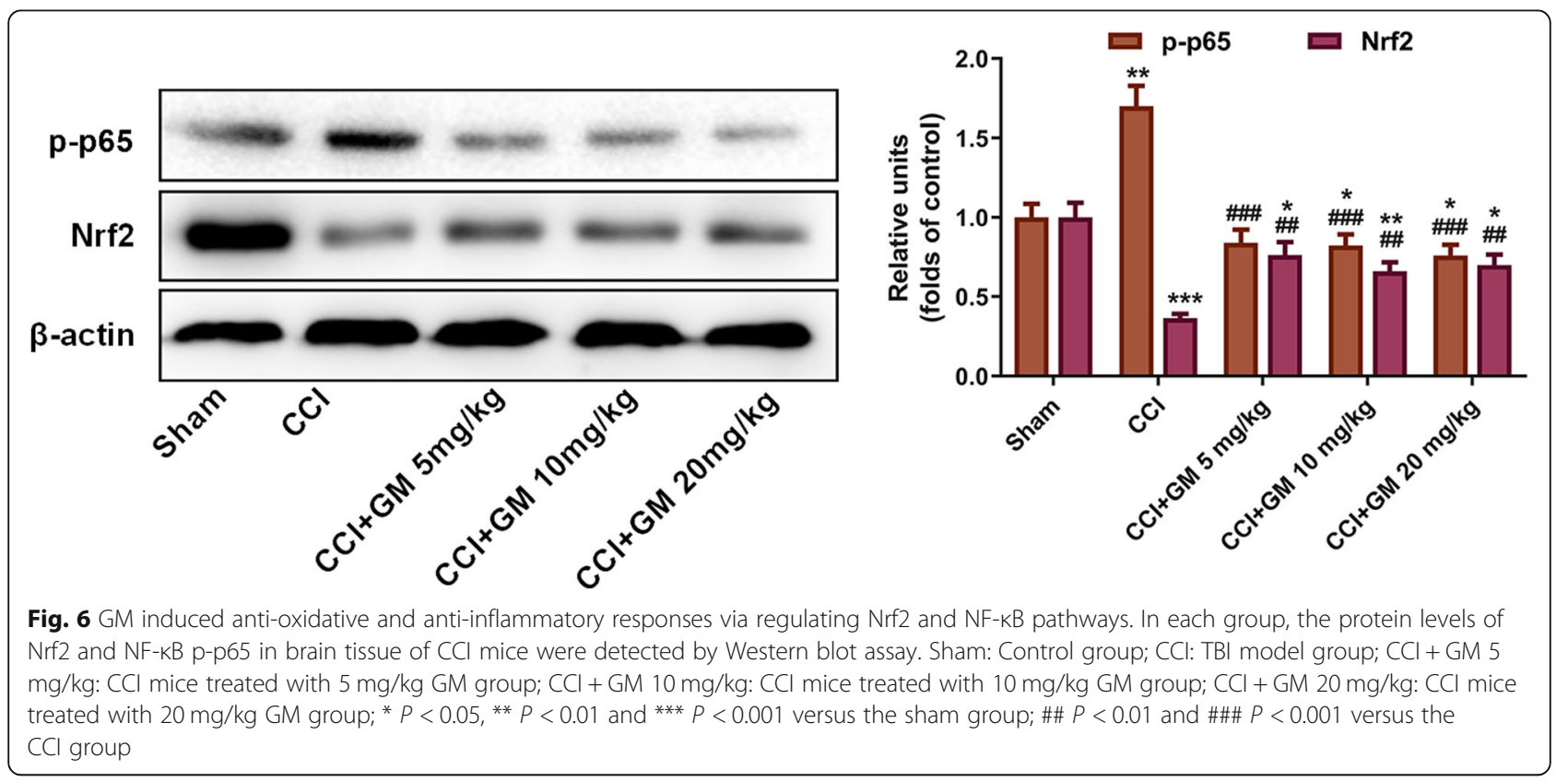




\section{Conclusion}

In summary, current research implies that GM can ameliorate the neurological dysfunction, inflammation and oxidative stress induced by TBI, probably via inhibiting NF- $\mathrm{BB}$ signaling activating Nrf2 pathway. This study not only explores the new mechanism of GM improving TBI injury but also provides clues for the therapeutic strategy of TBI.

\section{Supplementary Information}

The online version contains supplementary material available at https://doi. org/10.1186/s12906-020-03175-0.

Additional file 1. Supplementary materials Original image of Western

blot experiment in this study.

\section{Abbreviations}

GM: Germacrone; TBI: Traumatic brain injury; CCI: Controlled cortical impact; MPO: Myeloperoxidase; MDA: malondialdehyde; SOD: Superoxide dismutase; TNF-a: Tumor necrosis factor a; IL-1 $\beta$ : Interleukin-1 $\beta$; IL-6: Interleukin-6; ROS: Reactive oxygen species; Nrf2: Nuclear factor carotenoid 2 related factor 2; HE: Hematoxylin and eosin; qRT-PCR: Quantitative real-time polymerase chain reaction; GAPDH: Glyceraldehyde 3-phosphate dehydrogenase

\section{Acknowledgments}

Not applicable.

\section{Authors' contributions}

Conceived and designed the experiments: CLZ, SJZ, XYN; Performed the experiments: LW; Statistical analysis: SQL; Wrote the paper: SJZ, BGL, LW; Performed the revision: SJZ, BGL, SFG, YZX; Provided the funding and materials: XYN. All authors read and approved the final manuscript.

\section{Funding}

This study is supported by the Medical Research Project of Linyi Central Hospital (Approval No. 20170032).

\section{Availability of data and materials}

The data used to support the findings of this study are available from the corresponding author upon request.

\section{Ethics approval and consent to participate}

The protocols regarding all animal experiments in this study were approved by the Institutional Animal Care and Use Committee of Affiliated Hospital of Jining Medical University.

\section{Consent for publication}

Not applicable.

\section{Competing interests}

The authors declare that they have no competing interests.

\section{Author details}

'Department of Neurology, Linyi Central Hospital, Linyi 276400, Shandong, China. ${ }^{2}$ Department of Anesthesiology, Linyi Central Hospital, Linyi 276400, Shandong, China. ${ }^{3}$ Department of Intensive Care Unit 2, Affiliated Hospital of Jining Medical University, Jining 272000, Shandong, China. ${ }^{4}$ Department of Gastrointestinal Surgery, Affiliated Hospital of Jining Medical University, Jining 272000, Shandong, China. ${ }^{5}$ Department of Radiotherapy, Linyi Central Hospital, Linyi 276400, Shandong, China.
Received: 3 August 2020 Accepted: 3 December 2020

Published online: 05 January 2021

\section{References}

1. Singleton Q, Vaibhav K, Braun M, Patel C, Khayrullin A, Mendhe B, et al. Bone marrow derived extracellular vesicles activate osteoclast differentiation in traumatic brain injury induced bone loss. Cells. 2019:8:63.

2. Loane DJ, Faden Al. Neuroprotection for traumatic brain injury: translational challenges and emerging therapeutic strategies. Trends Pharmacol Sci. 2010;31:596-604.

3. Lozano D, Gonzales-Portillo GS, Acosta S, de la Pena I, Tajiri N, Kaneko Y, et al. Neuroinflammatory responses to traumatic brain injury: etiology, clinical consequences, and therapeutic opportunities. Neuropsychiatr Dis Treat. 2015;11:97-106

4. $\quad X u H$, Wang Z, Li J, Wu H, Peng Y, Fan L, et al. The polarization states of microglia in TBl: a new paradigm for pharmacological intervention. Neural Plast. 2017;2017:5405104

5. Missault S, Anckaerts C, Blockx I, Deleye S, Van Dam D, Barriche N, et al. Neuroimaging of subacute brain inflammation and microstructural changes predicts long-term functional outcome after experimental traumatic brain injury. J Neurotrauma. 2019;36:768-88.

6. Chen S, Dong Z, Cheng M, Zhao Y, Wang M, Sai N, et al. Homocysteine exaggerates microglia activation and neuroinflammation through microglia localized STAT3 overactivation following ischemic stroke. J Neuroinflammation. 2017;14:187.

7. Fann DY, Lim YA, Cheng YL, Lok KZ, Chunduri P, Baik SH, et al. Evidence that NF-KB and MAPK signaling promotes NLRP inflammasome activation in neurons following ischemic stroke. Mol Neurobiol. 2018;55:1082-96.

8. Chen X, Wu S, Chen C, Xie B, Fang Z, Hu W, et al. Omega-3 polyunsaturated fatty acid supplementation attenuates microglial-induced inflammation by inhibiting the HMGB1/TLR4/NF-kB pathway following experimental traumatic brain injury. J Neuroinflammation. 2017;14:143.

9. Thanan R, Oikawa S, Hiraku Y, Ohnishi S, Ma N, Pinlaor S, et al. Oxidative stress and its significant roles in neurodegenerative diseases and cancer. Int J Mol Sci. 2014:16:193-217.

10. Gold R, Kappos L, Arnold DL, Bar-Or A, Giovannoni G, Selmaj K, et al. Placebo-controlled phase 3 study of oral BG-12 for relapsing multiple sclerosis. N Engl J Med. 2012;367:1098-107.

11. Wang B, Zhu X, Kim Y, Li J, Huang S, Saleem S, et al. Histone deacetylase inhibition activates transcription factor Nrf2 and protects against cerebral ischemic damage. Free Radic Biol Med. 2012;52:928-36.

12. Li L, Zhang $X$, Cui L, Wang L, Liu H, Ji H, et al. Ursolic acid promotes the neuroprotection by activating $\mathrm{Nrf} 2$ pathway after cerebral ischemia in mice. Brain Res. 2013;1497:32-9.

13. Sun Y, Li L, Wu J, Gong B, Liu H, Wu T, et al. Germacrone attenuates cerebral ischemia/reperfusion injury in rats via antioxidative and antiapoptotic mechanisms. J cell Biochem. 2019;120:18901-9.

14. Lim MS, Choung SY, Jeong KW. Germacrone inhibits estrogen receptor amediated transcription in MCF-7 breast Cancer cells. Phytother Res. 2016;30: 2036-43.

15. Wu T, Yin F, Kong H, Peng J. Germacrone attenuates cerebral ischemia/ reperfusion injury in rats via antioxidative and antiapoptotic mechanisms. J Cell Biochem. 2019;120:18901-9.

16. Wang Z, Zhuo F, Chu P, Yang X, Zhao G. Germacrone alleviates collageninduced arthritis via regulating Th1/Th2 balance and NF-KB activation. Biochem Biophys Res Commun. 2019;518:560-4.

17. An JF, Sun Y, Zhang QL, Zhang FL, Zhang JL. The effects of germacrone on lipopolysaccharide-induced acute lung injury in neonatal rats, Cell Mol Biol (Noisy-le-grand). 2014;60:8-12.

18. Sun Y, Li L, Wu J, Gong B, Liu H. Germacrone cooperates with dexmedetomidine to alleviate high-fat diet-induced type 2 diabetes mellitus via upregulating AMPKa1 expression. Exp Ther Med. 2019;18:3514-24.

19. Myer DJ, Gurkoff GG, Lee SM, Hovda DA, Sofroniew MV. Essential protective roles of reactive astrocytes in traumatic brain injury. Brain. 2006;129:2761-72.

20. Tucker LB, Burke JF, Fu AH, McCabe JT. Neuropsychiatric symptom modeling in male and female C57BL/6J mice after experimental traumatic brain injury. J Neurotrauma. 2017:34:890-905.

21. Okun E, Griffioen K, Barak B, Roberts NJ, Castro K, Pita MA, et al. Toll-like receptor 3 inhibits memory retention and constrains adult hippocampal neurogenesis. Proc Natl Acad Sci U S A. 2010;107:15625-30. 
22. Jassam YN, Izzy S, Whalen M, McGavern DB, El Khoury J. Neuroimmunology of traumatic brain injury: time for a paradigm shift. Neuron. 2017;95:1246-65.

23. Zhang J, Yuan L, Wang S, Liu J, Bi H, Chen G, et al. Germacrone protects against oxygen-glucose deprivation/reperfusion injury by inhibiting autophagy processes in PC12 cells. BMC Complement Med Ther. 2020;20:77.

24. Cameron HA, Glover LR. Adult neurogenesis: beyond learning and memory. Annu Rev Psychol. 2015;66:53-81.

25. Yin $Y$, Qiu S, Li X, Huang B, Xu Y, Peng Y. EZH2 suppression in glioblastoma shifts microglia toward M1 phenotype in tumor microenvironment. J Neuroinflammation. 2017;14:220.

26. Tambuyzer BR, Ponsaerts P, Nouwen EJ. Microglia: gatekeepers of central nervous system immunology. J Leukoc Biol. 2009;85:352-70.

27. Zhang F, Yan C, Wei C, Yao Y, Ma X, Gong Z, et al. Vinpocetine inhibits NFKB-dependent inflammation in acute ischemic stroke patients. Transl Stroke Res. 2018:9:174-84.

28. Kim JW, Jin YC, Kim YM, Rhie S, Kim HJ, Seo HG, et al. Daidzein administration in vivo reduces myocardial injury in a rat ischemia/reperfusion model by inhibiting NF-kappaB activation. Life Sci. 2009;84:227-34.

29. Nita M, Grzybowski A. The role of the reactive oxygen species and oxidative stress in the pathomechanism of the age-related ocular diseases and other pathologies of the anterior and posterior eye segments in adults. Oxidative Med Cell Longev. 2016;2016:3164734.

30. Jeong YH, Park JS, Kim DH, Kim HS. Lonchocarpine Increases Nrf2/AREmediated antioxidant enzyme expression by modulating AMPK and MAPK signaling in brain astrocytes. Biomol Ther (Seoul). 2016;24:581-8.

31. Abdalkader M, Lampinen R, Kanninen KM, Malm TM, Liddell JR. Targeting Nrf2 to suppress Ferroptosis and mitochondrial dysfunction in Neurodegeneration. Front Neurosci. 2018;12:466

32. Chen X, Wang H, Zhou M, Li X, Fang Z, Gao H, et al. Valproic acid attenuates traumatic brain injury-induced inflammation in vivo: involvement of autophagy and the Nrf2/ARE signaling pathway. Front Mol Neurosci. 2018;11:117.

\section{Publisher's Note}

Springer Nature remains neutral with regard to jurisdictional claims in published maps and institutional affiliations.

Ready to submit your research? Choose BMC and benefit from:

- fast, convenient online submission

- thorough peer review by experienced researchers in your field

- rapid publication on acceptance

- support for research data, including large and complex data types

- gold Open Access which fosters wider collaboration and increased citations

- maximum visibility for your research: over $100 \mathrm{M}$ website views per year

At $\mathrm{BMC}$, research is always in progress.

Learn more biomedcentral.com/submissions 